\title{
A ficção e a história em $O$ ano da morte de Ricardo Reis de José Saramago: Ricardo Reis diante do espetáculo do mundo
}

\author{
Maria Elena Pinheiro Maia \\ Universidade Estadual Paulista - Araraquara
}

Ora, Ricardo Reis é um espectador do espetáculo do mundo, síbio se isso for sabedoria...

(Saramago 1988: 30)

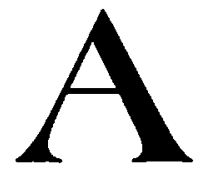

história por mais de um século procurou situar-se entre a Ciência e a Arte, embora não se julgasse obrigada a submeter-se nem aos métodos e normas científicos nem aos artísticos. Reivindicava a posição privilegiada de mediadora por reunir duas maneiras de interpretar o mundo que comumente estariam separadas.

Esse posicionamento da história não tem mais sustentação visto que modernamente não se justifica uma disjunção radical entre Arte e Ciência.

É indispensável, portanto, modificar a concepção convencional da história que valoriza o passado como um fim em si mesmo, e onde o eu do historiador tem a pretensão de ser totalmente neutro, para fazer emergir os fatos reais que constituiriam a história oficial das nações, e transformá-la numa disciplina dinâmica cujo objetivo seja trazer para o presente contribuições que ajudem a solucionar os problemas peculiares do nosso tempo, levando em consideração 
que é impossivel ter uma visăo totalmente imparcial e única do passado. É necessário que o historiador aceite como a maioria dos cientistas sociais " que os fatos, mais do que descobertos, são elaborados pelos tipos de pergunta que o pesquisador faz acerca dos fenômenos que têm diante de si ".'

É impossivel reconstituir o passado plenamente, por mais que o deseje o historiador, porque sempre haverá infinitas lacunas que deixarão de ser preenchiclas, ou por faltarem fontes e documentos ou pela própria leitura cleles, pois é natural que se realize um trabalho de seleção no qual determinados fatos passados que for:ım despercebidos possam hoje ser valorizados, dependendo do enfoque dado por quem faz a pesquisa.

Saramago escreve impulsionado por uma exigência imperiosa, que é a de livrar-se dessa visão redutora do passado fornecida pela historiografia, porque por mais que esta sc esforce, sua versāo será sempre parcial e seletiva. Não queremos dizer com isso que ele negue a história, mas que está consciente de que ela só pode movimentar-se dentro de determinados limites, visto ser elaborada e organizada de acordo com o ponto de vista do historiador.

E claro que ele faz também a sua particular leitura do mundo, mas através de uma pluralidade de visōes, fazendo com que várias vozes possam ser ouvidas ao mesmo tempo. Não nos apresenta uma verdade absoluta e imutável, não pretende fazer um discurso documental, mas sim iluminar, resgatar o que desse passado informe não foi dito, pois, como ele próprio afirma não é indiferente empregar a palavra passado ou bistória:

E certo que ambos os conceitos se referem ao tempo que foi, ao que denominamos tempo vivido, mas nenhum historiador, por exemplo, cometeria o lapso grosseiro de chamar a um livro 0 passado de Portugal em vez de História de Portugal. Ele sabe muito bem que o passado é o tempo informe e se escolheu ser historiador foi exatamente para fazer do passado história. Organizando-o. A história é, pois, passado organizado, mas nào

' WHITE, 1994. p. 56. 
todo passado apenas uma parte dele, uma seleção, uma antologia, um ajuste de factos. A história, digamo-lo assim, autoriza-se o ilogismo de tomar uma parte pelo todo c comete a proeza de fazĉla aceitar, pelo menos nos traços gerais, como indiscutível e inabalável. ${ }^{2}$

A invenção do presente, portanto, depende dessa incursão a esse passado informe, pleno, solto, descontínuo, com a intenção de reexaminá-lo, reordená-lo, de reavaliá-lo. Essa visão crítica c consciente do passado ajudar-nos-á a compreender melhor o presente e fornecer-nos-á dados para construirmos um futuro diferente, quem sabe melhor. E é essa esperança que encontramos presente no discurso de Saramago. Segundo Walter Benjamin uma das principais funções do escritor consciente, e Saramago o é, é a recuperação da esperança:

O dom de despertar no passado as centelhas da esperança é privilégio exclusivo do historiador convencido de que também os mortos não estarào em segurança se o inimigo vencer. E esse inimigo nào tem cessado de vencer"."

Saramago e Walter Benjamin entendem o conceito de passado de forma semelhante e consideram que o passado é um tempo a ser questionado e resgatado pela história e, por extensão, pela litematura: "O cronista que narra os acontecimentos sem distinguir entre os grandes e os pequenos, leva em conta a verdade de que nada do que um dia aconteceu pode ser considerado perdido para a história"."

Embora o discurso literário possa também documentar, não é esse seu objetivo. Ele não se confunde com o discurso histórico, pois possui regras próprias que o tornam um outro discurso e sua preocupação não é com a verdade documentada. Os limites entre

\footnotetext{
2 SARAMAGO, 1989. p. 45.

${ }^{3}$ BENJAMIN, 1994. p. 224.225.

BENJAMIN, 1994, p. 223.
} 
esses dois discursos nem sempre são nítidos, tornando difícil a demarcação entre eles, pois as contaminações tornam-se tão abundantes que nos levam a pensar, como nos afirma Saramago em O ano da morte, tudo falso, e verdadeiro. ${ }^{5}$

Já na própria epígrafe da obra a demarcaçào entre o real e o imaginário, sugerida por Fernando Pessoa, é tênue e imprecisa:

Se me disserem que é absurdo falar assim de quem nunca existiu, respondo que também nào tenho provas de que Lisboa tenha alguma vez existido, ou eu que escrevo, ou qualquer cousa onde quer que seja. ${ }^{6}$

É desse confronto entre o real e o imaginário que Saramago extrairá uma nova maneira de ver, ouvir e escrever, isto é, uma nova maneira de inventar o presente. Observemos o trecho a seguir, extraído de Levantado do chão, onde o narrador nos mostra o quanto são escorregadios os conceitos de verdade e mentira, pois a verdade pode nos levar a seu oposto e vice-versa:

São os homens feitos de maneira que mesmo quando mentem dizem outra verdade, e se pelo contrário é a verdade que querem lançar da boca para fora vai sempre com ela uma forma de mentir, mesmo nào havendo propósito.?

Na realidade o narrador deseja nos desorientar, deixar-nos sem saber em que terreno pisamos, indo de um lado a outro a nos questionar a respeito do que é real e do que é imaginário. Assim vai construindo a sua história de forma labirintica - como um verdadeiro "deus" - deixando-nos as pegadas para que possamos acompanhá-lo e decifrá-lo, chegando ao final dessa viagem de volta.

Levamos ainda em consideração que a dialética existente entre o falso e o verdadeiro é diferente da que existe entre o real e o imaginário, visto que a primeira é de ordem lógica e a segunda

'SARAMAGO, 1988. p. 198.

'SARAMAGO, 1988. p. 9.

'SARAMAGO, 1980. p. 284. 
ontológica. A relação entre o real e o imaginário nada tem a ver com a verdade, apenas com o verossímil, como nos confirma Saramago numa entrevista:

Neste livro nada é verdade, e nada é mentira. Não é verdade que Ricardo Reis tenha existido. Mas é verdade que se ele tivesse existido tinha sentido atribuir-lhe uma vida a partir da obra que deixou e dos dados que Fernando Pessoa nos deu dele. Mas é também verdade que Fernando Pessoa já nào estava vivo nessa altura. E no entanto é verossimil. Nào está vivo mas entra na história.Nada é mentira e nada é verdade no livro."

É tentando desvendar verdades ocultas, romper os limites entre o falso e o verdadeiro, diluir as fronteiras entre o histórico e o literário que Saramago tece o seu romance, aventurando-se a descobrir o nâodito, aquilo que poderia ter sido, como ele próprio justifica:

Creio bem que o que se subjaz a esta inquietaçào é a consciência da nossa incapacidade final para reconstituir o passado. E que, por isso, nào podendo reconstituí-lo somos tentados - sou-o eu, pelo menos - a corrigi-lo. Quando digo corrigir, corrigir a História, nåo é no sentido de corrigir os fatos da História, pois essa nunca poderia ser tarefa de romancista, mas sim de introduzir nela pequenos cartuchos que façam explodir o que até então parecia indiscutivel: por outras palavras, substituir o que foi pelo que poderia ter sido. Certamente se argumentará que se trata de um esforço gratuito, pouco menos que inútil, uma vez que aquilo que hoje somos nảo é do que poderia ter sido que resultou, mas do que efectivamente foi.

Simplesmente, se a leitura histórica, feita por via clo romance, chegar a ser leitura crítica, nào do historiador, mas da História, entåo essa nova operação introduzira, digamos, uma instabilidade, uma vibração, precisamente causadas pela pertubação do que poderia ter sido, quiçá tão útil a um entendimento do nosso presente como a demonstraçâo efectiva, provada e comprovada do que realmente aconteceu. 9

\footnotetext{
VALE, 1987. p. 2-3.

9 SARAMAGO, 1990 . p.19.
} 
Trilhando esses caminhos, Saramago penetrará no campo da história de modo ousado e crítico procurando preencher as lacunas com pequenos cartuchos que façam explodir o que até então parecia indiscutivel, entretecendo, assim, dados históricos num tecido ficcional predominante, questionando os valores culturais, políticos e sociais através de uma multiplicidade de vozes que lhe permitirá observar os fatos sob diversos ângulos. A essa nova maneira de relacionar-se com a história, Linda Hutcheon intitulou de metaficção bistoriogräfica. Diz a autora:

A metaficção historiográfica refuta os métodos naturais, ou de senso comum, para distinguir entre o fato histórico e a fiç̧ào. Ela recusa a visalo de que apenas a história tem uma pretensào à verdacle, por meio de questionamento da base dessa pretensão na historiografia e por meio da afirmaçào de que tanto a história como a ficção sào discursos, construtos humanos, sistemas de significaçào, e é a partir dessa identidade que as duas obtêm sua principal pretensão à verdade. Esse tipo de fiç̧ão pós-moderna também recusa a relegaçào do passado extratextual ao domínio da historiografia em nome da autonomia da arte ....

O ano da morte de Ricardo Reis pode ser classificado, de acordo com a teoria do pós-modernismo de Linda Hutcheon, como metaficção bistoriográfica, não só pelo modo como se apropria de acontecimentos e personagens históricos, analisando-os sob múltiplos pontos de vista e de maneira crítica e irônica dando-lhes um sentido novo e diferente, como ainda pela sua auto-referencialidade, isto é, pela constante alusão a sua própria situação discursiva. E é ao apontar para si próprio que o texto confronta-se com o seu outro. Portanto não se trata de romance histórico no sentido tradicional, que se volta totalmente ao passado para nele se integrar. Aqui o passado é revisitado de modo consciente sob a ótica do presente. Saramago, ao trabalhar a história em termos ficcionais, dá ao texto outras dimensões que acentuam o seu lado poético. Como

${ }^{10}$ HUTCHEON, 1991. p. 127. 
nos afirma Maria Alzira Seixo: "José Saramago não faz história, faz. romance, embora a história seja o 'outro' gênero da sedução de sua obra."II

A metaficção historiográfica elimina a ilusão da narrativa objetiva que se narra por si mesma, pois esse tipo de ficção reconhece que é impossivel alcançar com objetividade a arbitrária verdade histórica e nem é esse seu objetivo. Saramago deixa claro ao leitor esses mecanismos de composição.

Ricardo Reis reflete sobre o que viu e ouviu, acha que o objeto da arte nào é a imitaçào, que foi fraqueza censurável do autor escrever a peça no linguajar nazareno, ou no que supôs ser esse linguajar, esquecido de que a realidade nào suporta o seu reflexo, rejeita-o, so uma outra realidade, que seja, pode ser colocada no lugar daquela que se quis expressar, e sendo diferentes entre si, mutuamente de mostram, explicam e enumeram, a realidacle como invençào que foi, a invenção como realidade que será. ${ }^{2}$

O ano da morte de Ricardo Reis sustenta-se, então, entre duas dimensões intertextuais: de um lado a presença da obra pessoana e de outro todo o contexto histórico-social-político de $\mathrm{O}$ ano da morte, isto é, o ano de 1936.

Pelo título percebemos que a tônica do romance é o ano da morte e não sua personagem. Portanto interessa-nos saber quais foram os fatos históricos ocorridos nesse periodo e de que mancira foram tratados pelo autor.

Relembrando Linda Hutcheon, "uma das formas pós-modernas de incorporar literalmente o passado textualizado no texto presente é a paródia,"'3 a paródia entendida como modo de dessacralizar e questionar o passado. E é através da paródia que Saramago mostrará claramente a sua reação contra a visão da História imposta pelo regime salazarista.

\footnotetext{
"SEIXO, 1986. p. 24.

12 SARAMAGO, 1988. p. 109-110.

${ }^{13}$ HUTCHEON, 1991. p. 156.
} 
Bakhtin considera a paródia um elemento inseparável da sátira menipéia e de todos os gêneros carnavalizados. A sátira-menipéia formou-se da desintegração do diálogo socrático, mas isso não quer dizer que ela seja o resultado, o produto de sua decomposição, pois suas raizes remontam diretamente ao folclore carnavalesco. A denominação de sátira-menipéia deve-se a Menipo (século III a.C.). Suas caracteristicas mantiveram-se por várias épocas e sua influência perdura até hoje, tornando-se um dos principais veículos da cosmovisão carnavalesca da literatura. A menipéia caracteriza-se pela sua liberdade de invenção e fantasia. Suas estratégias estão subordinadas à função ideológica de provocar e exprimir a verdade, alcançando uma extrema capacidade de desnudar os acontecimentos, pois é capaz de analisá-los de vários ângulos.

Não nos estenderemos sobre o que concerne à sátira menipéia, mas somos obrigadas a utilizar o conceito de carnavalização para melhor entender as ambigüidades, contradições e oposições que emergem quando confrontamos a História oficial e a outra história. A cosmovisão carnavalizada através da subversão dos discursos da cultura oficial e instituída faz com que o lado implícito, oculto, dos eventos sociais tornem-se visiveis, pois, segundo Bakhtin, o carnaval elimina a distância entre os homens, rompe os limites da hierarquia social, faz conviver lado a laclo o profano e o sagrado, o oficial e o não oficial, revela caracteristicas do caráter e do comportamento das pessoas, tudo o que não seria possível no curso normal da vida. Ampliando essas oposiçōes para O ano da morte, teremos também lado a lado o bistórico e o ficcional, o vivo e o morto, o poeta e a camareira.

Conclui-se que o discurso carnavalizado será sempre um discurso que provocará mudanças, novas atitudes, onde os aspectos ocultos da natureza humana aflorarào. A paródia tem sempre um caráter positivo, pois ao renovar procura extrair do já estabelecido outras verdades, instalando, assim, a dúvida sobre os valores tradicionais e a possibilidade de transformação do presente. Segundo Maria Lúcia P. de Aragão: 
Carnavalizar, parodiar, é recusar e esvaziar, é dessacralizar sem descrer, pois só se discure e se leva em consideração aquilo em que se acredita. A paródia possui um caráter positivo, pois mata para fazer brotar novamente a criação. Recusa e esvazia o modelo original para recriar e preencher um modelo que lhe é próprio. ${ }^{14}$

E como parodiador que Saramago, com seu olhar crítico, iluminará esse passado histórico mostrando-nos o outro lado da História, o lado oculto pela elite governamental, onde predominam a miséria, a opressão, as injustiças, as perseguições políticas geradas pelo governo salazarista ditatorial e arbitrário. Vai buscar outras verdades, a da minoria, dos vencidos, dos marginalizados, dos excêntricos, ${ }^{15}$ daqueles que não entraram para a história oficial, pois a versão oficial é sempre produzida pela classe dominante, sendo os fatos históricos deformados por e em função dela e ao povo é apenas reservado o papel de colaborador passivo.

E esse passado histórico precisa ser reavaliado, não ingenuamente, mas de modo crítico e irônico, pois questioná-lo é uma maneira de poder entender melhor as inquietações, ansiedades e frustrações do momento presente. É mostrar que o destino do homem não está determinado, que é possível mudá-lo.

É como espectador do espetáculo do mundo que Ricardo Reis é inserido neste recorte do passado que Saramago deseja reviver. Época da ascensão de Salazar, que em 1932 tinha sido nomeado presidente do Conselho e Ministro das Finanças e que no momento dominava Portugal com sua doutrina mistificadora, compactuando com o fascismo e o nazismo que proliferavam pela Europa.

Salazar era tido por aqueles que usufruiam dos privilégios da situação como o sábio ditador. Mas a grande maioria da população vivia sob uma das tiranias mais asfixiantes da Europa. A paz interior

14 ARAGĩo, 1980. p. 22.

is Termo usado por Linda Hutcheon que dá a essa excentricidade um duplo sentido. Por um lado, são as personagens colocadas à margem da História oficial e por outro, os literalmente excêntricos, isto é, invulgares, como Reis tirado do mundo da ficção ou Fernando Pessoa como personagem já morta. 
era alcançada através de uma terrivel pressão policial (P.V.D.E.). Portugal pouco progredia. Muitos se expatriaram por falta de liberdade e de oportunidades de trabalho.

Reis, ao aportar em Lisboa, penetra neste ambiente sombrio, triste e silencioso, poderiamos até dizer assıstador pois "por gosto e vontade ninguém haveria de querer ficar neste porto."16 Chovia. A cidade estava alagada. As águas do Tejo, turvas. Sem dúvida ele chegara num mau tempo, tempo de opressão, de perseguiçōes, de miséria, tempo de ditadura que havia silenciado Lisboa, "desce sobre a cidade um silêncio, todos os sons são abafados, em surdina, parece Lisboa que é feita de algodão, agora pingando."17 Essa atmosfera abafada e opressora que envolve Lisboa durante toda a narrativa vem enfatizar a dificil viagem de volta que Ricardo Reis se propõe a empreender, redescobrir Portugal e conseqüentemente autoreconhecer-se. Sua volta causa estranheza até à P.V.D.E. que ao entrevistá-lo deixa transparecer sua indignação, pois os emigrantes portugueses raramente voltam do Brasil: "Sim, voltei, Porquê, Os emigrantes portugueses às vezes voltam, Do Brasil quase nunca." 18

É esse momento histórico conturbador que Saramago percorre com olhos críticos, analisando-o de outros pontos de vista que não o convencional, deixando aflorar inúmeras vozes que se contrastam para que venham à tona as verdades ocultas pela História oficial.

Como narrador onisciente é capaz de ler o pensamento de seus personagens, fazer profecias e recorrer muitas vezes a acontecimentos passados não só em Portugal, mas em toda a Europa, de onde chegam as notícias através de jornais, rádio, propaganda. Analisa como essas notícias são decodificadas de diferentes modos: há os que acreditam piamente nessas comunicações de massa, como o Dr. Sampaio, e os que questionam a sua veracidade, como Lídia.

\footnotetext{
${ }^{16}$ SARAMAGO, 1988. p. 12.

"SARAMAgO, 1988. p. 64.

${ }^{18}$ SARAMAGO, 1988. p. 190.
} 
As referências políticas ocupam boa parte do romance. Fazemnos saber, entre outros acontecimentos, que na Espanha, a Guerra Civil opôs de um lado os nacionalistas, chefiados por Francisco Franco e de outro os republicanos de Manuel Azaña, o que custou a vida a um milhão de pessoas, servindo de campo de experiência para as armas alemãs que seriam usadas na II Guerra Mundial; na Itália o fascismo liderado por Mussolini solidifica-se, destacando-se nesse contexto a Alemanha nazista, dada sua influência em Portugal. Hitler é o modelo ideal e a sua aproximaçào com Salazar traz resultados profícuos para o regime português.

No hotel Bragança, onde se hospeda, Reis conhece o Dr. Sampaio, admirador profundo de Salazar, que representa a voz da elite privilegiada de Portugal. Atentemos para a passagem abaixo que exemplifica a sua visão deste momento político.

A nós o que nos vale, meu caro doutor Reis, neste cantinho da Europa, é termos um homem de alto pensamento e firme autoridade à frente do governo e do país [...], Não há comparação possível entre o Portugal que veio encontrar agora [...] é impossivel que não se tenha apercebido clas grandes transformações, o aumento da riqueza nacional, a disciplina, a doutrina coerente e patriótica, o respeito das outras nações pela pátria lusitana, sua gesta, sua secular história e seu império."

Um outro personagem que devemos ressaltar pela sua força simbólica é Marcenda, filha do Dr. Sampaio, jovem magra, frágil, apática e que possuia a mão esquerda paralisada, inerte. Oprimida pelo pai, não é capaz de alcançar sua própria idlentidade, preferindo não enxergar o que acontece a sua volta. A imobilidade da sua mão esquerda acentua a impossibilidade de lutar contra obstáculos que a vida lhe apresenta, prefere o silêncio, o não envolvimento, a resignação. Como diz Teresa Cristina Cerdeira da Silva:

Marcenda é a aventura do livro que foi sem ter sido, da musa nova que relembra a musa antiga e revela a sua própria falência, que é

"SARAMAGO, 1988. p. 137. 
semelhante à falência do heterônimo no tempo novo de 1936 . Se, para continuar a reviver 1936 na Europa, o heterônimo teria que assumir-se personagem na História, também a musa nova de molde antigo não pode sobreviver, é Marcenda, marcescível. ${ }^{30}$

A apatia de Marcenda diante das mentiras e arbitrariedades, a total submissão ao pai estão simbolicamente representadas pela inércia de sua mão, que metaforiza por sua vez a grande massa popular imobilizada pela opressão, a voz da oposição abafada, amortecida pela falaciosa ideologia do Estado Novo.

Contrastando com sua apatia diante dos acontecimentos do mundo, temos Lídia que representa a vontade e a força do povo. Moça feita, com seus 30 anos, baixa, morena, olhar triste, "mão castigada de trabalhos, áspera quase bruta, tão diferente das mãos de Cloé, Neera e a outra Lídia" ${ }^{21}$ e, principalmente, da resignada e conseqüentemente atrofiada mão de Marcenda.

Ela possui, ao contrário de Reis, uma visão real, concreta da situação política do país, sabe o que acontece aos que se opõem às normas pré-estabelecidas pelo governo. Teme pelo seu irmão Daniel e por outras pessoas fortes e decididas como ele que desejam uma pátria melhor, sem opressão, onde possam viver dignamente e sem medo. Lidia é suficientemente perspicaz para perceber que os jovens que entram voluntariamente para a Mocidade Portuguesa, organização criada à imitação da nazista e fascista, são manipulados pela propaganda marcada pela ideologia Salazarista - "Filho meu, diz Lídia a Ricardo Reis, não entra em semelhantes comédias." 22

A visão clara e objetiva de Lídia contrasta com a alienação de Ricardo Reis e Marcenda. Reis, embora passe grande parte de seu tempo lendo os jornais, é incapaz de decifrá-los, não consegue confrontar o que os jornais dizem com o que tem diante dos olhos (a P.V.D.E., o bodo, o povo sempre com a mão estendida a pedir

\footnotetext{
"SILVA, 1989. p. 184.

"SARAMAGO, 1988. p. 168.

"SARAMAGO, 1988. p. 364.
} 
esmola.). E Marcenda não tem a força obstinada de Lidia, deixa-se levar pelo pai, incapaz de impor sua própria vontade, de decidir seu destino.

A voz de Lídia, inicialmente fraca, vai se tornando tão mais forte e clara que até mesmo Reis admira: "às vezes não sei bem quem tu és. Sou uma criada de hotel, mas chama-te Lídia e dizes as coisas duma certa maneira. ${ }^{23}$ Como diz José Saramago em uma entrevista, Lídia "é uma personagem que se faz a si própria, no ato do discurso".24

Reis a vê como a mulher que serve para satisfazer os seus desejos fisicos e outras necessidades básicas. Ele não percebe que pouco a pouco está sendo conquistado por esta mulher forte, corajosa, sensual, de fibra, que lhe dedica com amor e despreendimento todos os seus momentos livres. Mesmo depois de beijá-la, ato de que ele antes se esquivava, nomeia-a "mulher desigual" 25 ao justificar a Fernando Pessoa porque não iria perfilhar a criança que Lídia esperava. Somente no último encontro as barreiras entre eles diluem-se e Reis a trata como companheira, comportando-se como um amoroso amante: "Lídia desceu a escada, contra o costume foi Ricardo Reis ao patamar, ela olhou para cima, ele fez-lhe um gesto de aceno, ambos sorriram, há momentos perfeitos na vida, foi este um deles." 26

Reis lutará até o final para permanecer impassivel diante de todos os acontecimentos. Não se apaixona por nada, nem por ninguém. Não reage diante da intensa humilhaçào daqueles que esperam o ano inteiro para receber o bodo, do atentado prematuro do Joâo de Lisboa, do triste espetáculo de Fátima, da possibilidade de ser pai, nem mesmo quando recebe uma contrafé proveniente da Polícia de Vigilância e Defesa do Estado (P.V.D.E.). Ao contrário,

\footnotetext{
23 SARAMAGO, 1988. p. 201.

${ }^{24}$ DUARTE, julho 86-dez. 88. p. 97.

${ }^{25}$ SARAMAGO, 1988. p. 361.

* SARAMAGO, 1988. p. 406.
} 
continua sempre decidido a seguir sua vocação de espectador do mundo.

Entra em contato com as notícias através dos jornais. São eles que compõem o elo entre o mundo inventado e o mundo real, mas não chega a notar, ou não quer, a gravidade da situação. Só um intelectual alienado, para quem sábio é aquele que se contenta com o espetáculo do mundo é capaz de ler e acreditar nos jornais manipulados por um regime autoritário. Na realidade essa alienação é apenas aparente, pois recusar-se a ver os acontecimentos do mundo, é mais cômodo. Admitir que as notícias dos jornais sejam falaciosas, significa para ele, que detesta mentiras, ter que posicionar-se, comprometer-se, negar seus princípios. E é exatamente através desse recurso, de tornar o jornal o veículo de inserção da personagem no mundo, que a ironia e a ambigüidade se instalam no texto. Tornam-se evidentes principalmente quando nos inteiramos do fato de que é criado um exemplar único do $N e w$ York Times, apenas com notícias que trazem tranqüilidade e convicção nos valores ideológicos do capitalismo, para que o milionário Rockfeller possa ser poupado das preocupações mundanas. Portanto será através de Lidia que Saramago denunciará a política opressora e arruinante de Salazar. ${ }^{27}$

Está no jornal, eu li, Não é do Senhor doutor que eu duvido, o que o meu irmão diz é que não se deve fazer sempre fé no que os jornais escrevem, [...] O senhor doutor é uma pessoa instruída, eu sou quase analfabeta, mas uma coisa eu aprendi, é que as verdades são muitas e cstão umas contra as outras, enquanto não lutarem não

${ }^{27}$ Queremos aqui ressaltar que, apesar de diferentes vozes exprimirem ideologias que se confrontam ou se contradizem, elas não são tratadas do mesmo modo pelo narrador, que ironicamente as diferencia, hierarquizandoas. Isso nos leva a questionar até que ponto o romance é dialógico no sentido bakhtiniano oncle o narrador age como organizador e participante sem julgar ou hierarquizar as ideologias expressas por diversas vozes. Se assim analisarmos, a plenivalência esperada de um texto que se quer dialógico não é totalmente encontrada. 
se saberá onde está a mentira [...] o meu irmào diz que se a igreja estivesse do lado dos pobres, para os ajudar na terra, os mesmos pobres seriam capazes de dar a vida por ela, para que ela nào caísse no inferno, onde está, l...] Será outra horrivel verdade, mas o meu irmão diz que enquanto os pobres estão na terra e padecem nela,os ricos jâ vivem no céu vivendo na terra. ${ }^{23}$

Como nos comprova o trecho acima transcrito, embora o romance se aproprie do discurso jornalistico, não tem pretensão nenhuma de atingir um realismo documental, pois sâo muitas as verdades, apenas tem como objetivo revelar esse discurso "como umá representação cultural, como um discurso sobre os acontecimentos históricos quase simultaneamente vividos e já implicados ideologicamente, lançando a desconfiança em relação à apresentação objetiva da História"," fato que já discutimos anteriormente.

Quando Reis aportou em Lisboa, levou consigo ao acaso o romance The god of the labyrinth de Herbert Quain. ${ }^{30}$ Esse fato percorre toda a obra, adquirindo um sentido altamente metafórico, porque é o próprio Reis que tece o seu labirinto, vagueando entre uma Lídia que não é a de suas Odes, mas uma "amazona de arco, flecha e durindana", ${ }^{31}$ que possui o vigor das mulheres do povo; uma Marcenda fragmentada, que tem a mão esquerda paralisacla c inútil, um ser frágil, marcescível e um morto, que o visita e que o conhece profundamente; além de todos esses complexos relacionalmentos, a leitura assiclua dos jornais com o objetivo de procurar sua própria identidade. E quanto mais ele se aprofunda nesses pontos de contato tão díspares, mais se sente desorientado. Assim sendo, durante todo o tempo que Reis permaneceu em Lisboa não

2* SARAMAGO, 1988. p. 388.

*) GOBBI, 1997. p. 150.

"Romance atribuido por Borges a Herbert Quain em Ficciones. Assim como o livro e seu autor, Reis também é uma criaçào ficcional, a quem seus criadores Borges e Pessoa dào estatuto de realidade.

"SARAMLGO, 1988. p. 174. 
conseguiu ler o livro como também não conseguiu encontrar a saída dessa grande teia por ele tecida. A travessia do leitor por essa teia labiríntica e ambigua também será dificultosa, pois como já dissemos, são muitos os percursos que o texto nos oferece e qualquer deles que percorramos, nele sempre encontraremos pistas para novos descobrimentos e indagações. Afinal quem era Reis nesse labiríntico Portugal de 1936? Atentemos para a passagem do texto:

The god of the labyrinth, seu autor Herbert Quain, Irlandês também, por não singular coincidência, mas o nome, esse sim, é singularíssimo, pois sem máximo erro de pronúncia se poder ler, Quem, repare-se Quain, Quem. ${ }^{32}$

Lídia poderia ter sido opção para que ele saísse desse labirinto e assumisse o papel de cidadão consciente dos problemas de seu país. Mas quando os acontecimentos se agravam, com a morte de Daniel, irmão de Lídia, ele percebe que embora deseje, não é tão fácil ser alienado diante de tantas injustiças. Prefere, então, morrer a ceder.

atira-se para cima da cama desfeita, esconde os olhos com o antebraço para poder chorar à vontade, lágrimas absurdas, que esta revolta não foi sua, sábio é o que se contenta com o espetáculo do mundo, hei-de dizê-lo mil vezes, que importa àquele a quem já nada importa que um perca e outro vença. ${ }^{33}$

Reis conclui que só the resta um caminho, partir com Fernando Pessoa, pois é impossivel viver sem incomodar-se com seus semelhantes, ser indiferente diante dos acontecimentos do mundo. Opta, portanto, pela sua partida, retornando enfim, a sua irreal existência, levando consigo o livro The god of the labyrinth. "Já me custa ler, disse, mas mesmo assim vou levá-lo, Para quê, Deixo o mundo aliviado de um enigma." ${ }^{34}$

\footnotetext{
"2 SARAMAGO, 1988. p. 23.

"S SARAMAGO, 1988. p. 411-412.

34.SARAMAGO, 1988. p. 415.
} 
O labirinto representa esse mundo caótico no qual se acha Ricardo Reis e para o qual não encontra solução. Deixa-se derrotar pela incapacidade ou o não desejo de decifrar o enigma. E o fato de partir levando consigo o livro de que quer o mundo aliviado representa, na realidade, o seu desejo de carregar todas as experiências por ele vividas, jả que não podem ser apagadas de sua memória, assim como é impossível o seu desejo de recolocar o livro de onde o retirara, anulando esse tempo vivido. The god of the labyrinth simboliza, então, a história de sua vida, o registro dos encontros e desencontros pelos quais passou neste conturbado ano de 1936 e a comprovação da impossibilidade de apenas contemplar o espetáculo do mundo. Deixando implícito a afirmação de que é preciso ver, de que é inevitável agir.

\section{Referências Bibliográficas}

ARAGÃO, M. L. P. A paródia em a força do destino. Revista Tempo Brasileiro. (n.62), Rio de Janeiro, julho-setembro de 1980. p.22.

BAKHTIN, M. Problemas da poética de Dostoievski. Trad. Paulo Bezerra. 2. ed. Rio de Janeiro: Forense Universitário, 1997.

BENJAMIN, W. Sobre o conceito da história . In: - Obras Escolbidas: Magia e Técnica, Arte e Política. 7. ed. Sào Paulo: Editora Brasiliense, 1994. V. I. p. 224-225.

BORGES, J. L. Fiç̧ôes. Lisboa: Livros do Brasil, 1969.

BUENO, A. F. O poeta no labirinto: A construção do personagem em $O$ ano da morte de Ricardo Reis. 1994. Dissertaçào (Mestrado) - Faculdade de Letras, Unicamp, Campinas.

DAL FARRA, M. L. Para uma 'biografia' de um monárquico sem rei: Ricardo Reis. Estudos Portugueses e Africanos. Campinas, 1986. p. 77-87.

DUARTE, L. P. et al. José Saramago, tecedor da História. Boletim do Centro de Estudos Portugueses, Belo Horizonte, FALE/UFMG, n.12, 1988.

GOBBI, M. V. Z. De fato, ficção. 1997. Tese (Doutorado) - Universidade de São Paulo, São Paulo. 
HUTCHEON, L. Poética do pós- modernismo. História - Teoria - Ficção. Trad. Ricardo Cruz. Rio de Janeiro: Imago Editora, 1991. (Série Logoteca)

HUTCHEON, L. Uma teoria da paródia. Trad. Teresa Louro Pérez. Lisboa: Ediçōes 70, 1985.

NETTO, J. P. Portıgal do Fascismo à Reuoluçâo. Porto Alegre: Mercado Aberto, 1986.

PASCHKES, M. L. A. A ditadura salazarista. São Paulo: Editora Brasiliense, 1985. (Coleçào: Tudo é história. 106)

SARAMAGO, J. O ano da morte de Ricardo Reis. 3. ed. Sào Paulo: Companhia das Letras, 1988

SARAMAGO, J. História e Ficçào. Jornal de Letras, Lisboa, ano X, n.400, 6 a 12 de março, 1990. p. 17-20.

SARAMAGO, J. Sobre a invençào do presente. Jornal de Letras, Lisboa, Ano VIII, n.317, 28 de fevereiro a 06 de março de 1989. p.45.

SEIXO, M. A. A palatra do romance. Lisboa: Livros Horizonte, 1986.

SILVA, T. C. C. José Saramago entre a bistória e a fição: uma saga de Portugueses. Lisboa: Publicações Dom Quixote, 1989.

VALE, F. Neste livro nada é verdade e nada é mentira. Jornal de Letras, Lisboa, Ano IV, n.121, 30 de outubro a 05 de novembro, 1984. p. 2-3.

VIANA, M. J. M. O ano da morte de Ricardo Reis: a encenação da impossibilidade. Boletim do Centro de Estudos Portıgueses, Belo Horizonte, FALE/UFMG, n.13, 1991

WHITE, H. Trópicos do Discurso. Ensaios de Cultura. Vol. 6. São Paulo: Edusp, 1994. p.56. 


\section{Resumo}

A configuriçio intertextual em $O$ ano da morte de Ricardo Reis de José Saramago é extremamente nítida. Seu título já anuncia a apropriaçio discursiva: Ricardo Reis, heterônimo de Pessoa, agora surge como personagem de Saramago. Um ser de papel, dono de uma biografia previamente conhecida, seri inserido num momento hisı́rico crucial de Portugal, onde a sua tìo propagada posiçào diante da vida - "sábio é o que se contenta com o espetáculo do mundo" - será colocada à prova. Saramago percorre com olhos críticos esse passado, analisando-o de outros pontos de vista que nalo o convencional, deixando aflorar inúmeras vozes que se contrastam para que venham a tona as verdades ocultas pela História oficial.

Assim sendo esta obra distancia-se do romance histórico tradicional podendo ser classificada, de acordo com a teoria do pós-modernismo de Linda Hutcheon, como metafiç̧äo bistoriogräfica.

\section{Résumé}

Ricardo Reis devant le spectacle du monde dans $O$ ano da morte de Ricardo Reis de José Saramago.

La configuration intertextuelle dans $O$ ano da mone de Ricardo Reis est extrèmement nette. Son titre annonce déjà l'appropriation discursive: Ricardo Reis, héteronyme de Pessoa, à présent, apparaît comme personnage de Saramago. Um ètre de papier, maître d'une biographie au préalable connue, il sera inclus dans un moment historique crucial du Portugal, où sa position si répandue devant la vie - "sage c" est ce que se contente avec le spectncle du monde" - elle sera mise a l'epreuve.

Saramago parcourt avece les yeux critiques ce passé, en l'analysant d'autres points de vue que n'est pas le conventionnel, en laissant affleurer des nombreuses voix que s'opposent pour qu' il apparaisse des vérités occultes pour l'Histoire Officielle.

Done cette oeuvre s'êloigne du roman historique traditionnel pouvant être classifiée, selon la théorie du pos-modernisme de Linda Hutcheon, comme métafiction Historique. 